\title{
EFECTO DE TRES FRECUENCIAS DE RIEGO SOBRE EL CICLO DEL CULTIVO, CONTENIDO NUTRICIONAL DE LA SEMILLA Y RENDIMIENTO DE AQUENIOS EN CUATRO CULTIVARES DE GIRASOL (HELIANTHUS ANNUUS L.)
}

\author{
EFFECT OF IRRIGATION ON CROP SEASON, SEED NUTRITIVE \\ CONTENT AND ACHENE YIELD IN FOUR SUNFLOWER \\ (HELIANTHUS ANNUUS L.) CULTIVARS
}

\author{
Jesús Rafael Méndez-Natera ${ }^{1}$; José Miguel Cedeño-Gómez ${ }^{1}$; Jesús Rafael Cedeño ${ }^{1}$; \\ José Alexander Gil-Marín ${ }^{1}$; Luis Khan-Prado ${ }^{1}$
}

\begin{abstract}
RESUMEN
El girasol con riegos suplementarios oportunos y suficientes produciría una planta de mayor porte y mayor superficie foliar, factores que luego se traducirían en un buen rendimiento. El objetivo del presente trabajo fue evaluar el efecto de tres frecuencias de riego sobre el ciclo del cultivo, contenidos de aceite y proteínas de las semillas y rendimiento de aquenios por planta en cuatro cultivares de girasol. El diseño estadístico utilizado fueron parcelas divididas con tres repeticiones, las parcelas principales fueron las frecuencias de riego y las subparcelas los cultivares de girasol. No se encontraron diferencias significativas para ninguna de las fuentes de variación para el contenido de aceite $(29,21 \%)$. El cultivar más precoz en floración fue M-733, mientras que el más tardío fue S-515. El cultivar H-18-A presentó el menor contenido de proteínas en comparación con los otros tres cultivares, los cuales no difirieron entre sí. H-18-A presentó rendimientos de aquenios/planta similares a los de M-733 y GV-28074, pero superiores al de S-515. El mayor contenido de proteínas se registró en plantas cultivadas en las frecuencias de riego de 9 y 12 días, superando al de las plantas regadas cada 6 días. En los intervalos de riego de 6 y 12 días, el cultivar más precoz a maduración fue GV-28074, mientras que en la frecuencia de riego de 9 días, el cultivar más precoz fue M-733. La comparación dentro de los cultivares indicó que H-18-A tuvo un ciclo de cultivo similar bajo las tres frecuencias de riego, mientras que S-515 y GV-28074 fueron más precoces a maduración en la frecuencia de 6 días en comparación con la frecuencia de 9 y 12 días; el cultivar M-733 fue más precoz en las frecuencias de 9 y 12 días en comparación con la frecuencia de 6 días. Se puede concluir que las diferentes frecuencias de riego afectaron el comportamiento de los cuatro híbridos en relación al ciclo total del cultivo. El incremento en las frecuencias de riego ocasionó un incremento del contenido de proteínas del aquenio sin importar el cultivar utilizado.
\end{abstract}

Palabras clave: Girasol, Helianthus annuus, frecuencias de riego.

\begin{abstract}
The application of appropriate supplementary irrigations in sunflower would produce a better plant architecture and more foliage area, traits that will guide a better yield. The objective of this work was to evaluate the effect of three irrigation intervals on crop season, seed oil and protein contents and achene yield per plant in four sunflower cultivars. A split-plot design was used with three replications, the irrigation intervals were the main plots and sunflower cultivars were the sub-plot. There were not significant differences for cultivars, irrigation intervals and irrigation intervals $x$ cultivars interaction for seed oil content (29.21\%). The earlier cultivar at flowering was M-733, while the later one was S-515. Cultivar H-18-A had the smaller seed protein content in comparison with the other three cultivars, which did not differ among them. H-18-A had a similar seed yield per plant to those of M-733 and GV-28074, but bigger than those of S-515. The bigger seed protein content occurred in plants growing at 9-day and 12-day irrigation intervals, surpassed those of plants growing at 6-day irrigation intervals. Cultivar GV-28074 was earlier at harvest growing at 6-day and 12-day irrigation intervals, while M-733 was earlier at harvest at 9-day irrigation intervals. The comparison among cultivars indicated that H-18-A had a crop cycle similar under the three irrigation intervals, while S-515 and
\end{abstract}

1 Escuela de Ingeniería Agronómica, Núcleo Monagas, Universidad de Oriente. Avenida Universidad, Campus Los Guaritos, Venezuela. E-mail: jmendezn@cantv.net

Fecha de Recepción: 13 Enero 2006

Fecha de Aceptación: 22 Marzo 2006 
GV-28074 were earlier maturing at 6-day irrigation intervals than 9-day and 12-day ones, cultivar M-733 was earlier maturing at 9-day and 12-day irrigation intervals than 6-day interval. It can be concluded that the performance of the total cycle in the four cultivars was affected by the irrigation intervals. The increased irrigation intervals produced an increment of the seed protein content no matter the cultivar used.

Key words: Sunflower, Helianthus annuus, irrigation frequency.

\section{INTRODUCCIÓN}

El girasol si bien tiene una resistencia notable a la sequía, debido a su profuso sistema radicular y su alto poder de succión, con riegos suplementarios oportunos y suficientes produce una planta de mayor porte y mayor superficie foliar, factores que luego se traducen en un buen rendimiento (Saumell, 1980). Por otra parte, el suministro de agua es un factor crítico para la formación del aceite, particularmente en el periodo entre la formación de los capítulos florales y la maduración completa de las semillas (Shiv Raj, 1985). Adicionalmente, la falta de humedad del suelo puede afectar negativamente tanto el comienzo de la floración, así como el ciclo total del cultivo.

Según Vrậnceanu (1977), el girasol consume importantes cantidades de agua, tanto en la época de crecimiento activo como sobre todo en la época de la formación y proceso de llenado de las semillas, y los recursos de agua en el suelo determinan las mayores diferencias de tiempo y espacio de las cosechas, representando el factor de vegetación principal en las zonas con precipitaciones anuales insuficientes, el girasol demuestra gran adaptabilidad a las condiciones no favorables, así como gran resistencia a la falta de agua, en función del modo de utilización de estas menores cantidades de agua en el suelo, pero aunque el girasol es una planta resistente a la sequía, da producciones elevadas solamente cuando está bien abastecido de agua. Si la sequía es de larga duración y se manifiesta bien como insuficiencia de agua en el suelo o como baja humedad relativa, las plantas, aunque no mueren, tienen importantes modificaciones en el crecimiento, desarrollo y actividad funcional; la sequía en el suelo reduce la absorción de elementos nutritivos, influyendo de este modo en el crecimiento de la planta en cuanto al peso y altura. El efecto negativo de la sequía se manifiesta también de forma evidente sobre la acumulación de aceite en las semillas. El girasol tiene dos épocas críticas frente a la sequía: 1) época de iniciación de la formación del capítulo (final de la fase de diferenciación del receptáculo y formación de las emergencias florales) y comienzo de la floración, que afecta más fuertemente a la producción de semillas y 2) época que sigue inmediatamente a la floración, cuando tiene lugar la formación y el proceso de llenado de las semillas, y que es cuando el déficit de agua determina considerables pérdidas en el porcentaje y producción de aceite.

Alba-Ordóñez y Llanos-Company (1990) indicaron que el estrés hídrico afecta al girasol disminuyendo su área foliar y acelerando la senescencia. Esto conlleva una disminución en la radiación interceptada por el cultivo que, unido a una menor tasa de fotosíntesis, hace que la producción de biomasa y, por tanto, los rendimientos, se reduzcan considerablemente. El estrés hídrico también afecta directamente a los órganos reproductivos, reduciendo el número de semillas por capítulo debido a una fecundación defectuosa o al aborto de flores. Asimismo, se produce un descenso en el contenido de aceite de las semillas. Saumell (1980) indicó que durante los 40 a 50 días a partir de la siembra el girasol suele consumir entre el 20 y el $25 \%$ del total de agua necesaria para todo su ciclo y lo hace de la humedad disponible en las capas superiores, unos 40 a $50 \mathrm{~cm}$, luego, durante la formación del capítulo y la floración, o sea, unos 30 a 40 días absorbe otros 40 a $50 \%$ del total, pero a profundidades intermedias $(70-80 \mathrm{~cm})$. Por último, para la fase de formación de frutos y semillas, que dura 25 a 30 días, absorbe el 30 a $35 \%$ restante, a unos 100 a $120 \mathrm{~cm}$ de profundidad. Durante la maduración no requiere humedad sino, todo lo contrario, la mayor sequedad posible. Esta fase comprende los últimos 25 a 30 días del ciclo, antes de la cosecha.

Es importante saber el efecto que tiene el riego sobre el ciclo del cultivo tanto a nivel de floración como de maduración, es decir, si el riego retrasa o adelanta la floración y la cosecha del cultivo, así como también conocer el efecto de diferentes intervalos de riego sobre la calidad nutricional del aquenio de girasol. El presente trabajo se realizó con el objetivo de evaluar el efecto de tres frecuencias de riego sobre el ciclo del cultivo, contenidos de aceite y proteínas de las semillas y rendimiento de aquenios por planta 
en cuatro cultivares de girasol en el Valle del Río Guarapiche, en el estado Monagas, Venezuela.

\section{MATERIALES Y MÉTODOS}

El presente trabajo se realizó en el Sistema de Riego del Río Guarapiche, Sector Las Piñas, ubicado a $2 \mathrm{~km}$ de la ciudad de Maturín, estado Monagas, localizado a $9^{\circ} 45^{\prime} 36^{\prime \prime}$ Latitud Norte y $63^{\circ} 11^{\prime} 23^{\prime \prime}$ Longitud Oeste y a 40 m.s.n.m. Se utilizaron los híbridos de girasol M-733, GV-28074, H-18-A y S-515. Cada parcela principal estuvo constituida por tres surcos de $23 \mathrm{~m}$ de longitud, separados $0,70 \mathrm{~m}$ entre sí. Entre cada parcela principal se dejó un surco muerto (sin riego) para evitar el movimiento horizontal del agua de una parcela a otra. Cada subparcela estuvo formada por tres hileras de $5 \mathrm{~m}$, considerándose para efecto de evaluación sólo la hilera central, dejando las otras dos como bordura. El área experimental total fue de $579,6 \mathrm{~m}^{2}$, el área efectiva fue de $378 \mathrm{~m}^{2}$ y el área efectiva cosechada fue de $126 \mathrm{~m}^{2}$.

La distancia entre plantas fue de $0,20 \mathrm{~m}$ y entre hileras de $0,70 \mathrm{~m}$, con tres hileras de $5 \mathrm{~m}$ por tratamiento. El diseño estadístico utilizado fue el de parcelas divididas con tres repeticiones, siendo las parcelas principales las frecuencias de riego de 6,9 y 12 días y las subparcelas los cultivares de girasol. El cuadro 1 muestra el análisis de las características químicas y físicas del suelo donde se llevó a cabo el experimento, realizado en el Laboratorio de Análisis de Suelos y Aguas (LABSAS) de la Universidad de Oriente en Maturín, estado Monagas. La preparación del terreno consistió en un pase de arado, tres pases de rastra y un pase de surcado. La fertilización se realizó en bandas enterradas a razón de $600 \mathrm{~kg}$ de 12-24-12 CP/ha, cinco días después de la siembra y el reabono se realizó en bandas enterradas a razón de $200 \mathrm{~kg}$ de urea/ha a los 20 días después de la siembra. El control de malezas se realizó en forma

Cuadro 1

Algunas características químicas y físicas donde se realizó el experimento con cuatro cultivares de girasol evaluados en parcelas del Sistema de Riego "Santa Elena de las Piñas", del Río Guarapiche, Maturín, estado Monagas, Venezuela

\begin{tabular}{|c|c|c|c|c|}
\hline \multirow{2}{*}{ Características } & \multicolumn{3}{|c|}{ Estratos (cm) } & \multirow{2}{*}{ Metodología $^{1}$} \\
\hline & $0-20$ & $20-40$ & $40-60$ & \\
\hline $\mathrm{pH}$ & 5,5 & 5,7 & 5,9 & Potenciómetro (1:1) \\
\hline Materia Orgánica (\%) & 1,56 & 1,12 & 0,78 & Walkley-Black, colorímetro \\
\hline $\mathrm{P}(\mathrm{ppm})$ & 51,8 & 39,9 & 30,0 & Bray $\mathrm{N}^{\circ} 1$, Azul, Mol Ac. Asc. \\
\hline $\mathrm{Al}$ (meq/100 g suelo) & $\ldots$ & $\ldots$ & $\ldots$ & $\mathrm{KCl}, 1 \mathrm{~N}$ Titulación \\
\hline $\mathrm{Ca}$ (meq/100 g suelo) & 6,52 & 5,69 & 4,95 & KCl, 1 N. Absorc. Atómica \\
\hline $\mathrm{Mg}$ (meq/100 g suelo) & 1,18 & 1,03 & 0,70 & KCl, 1 N. Absorc. Atómica \\
\hline H (meq/100 g suelo) & 0,15 & 0,10 & 0,15 & KCl, 1 N. Absorc. Atómica \\
\hline K (meq/100 g suelo) & 0,03 & 0,01 & 0,01 & Bray $\mathrm{N}^{\mathrm{o}} 1$, Absorc. Atómica \\
\hline CICE (meq/100 g suelo) & 7,73 & 6,73 & 5,66 & $\sum$ de Cationes $(\mathrm{Ca}, \mathrm{Al}, \mathrm{Mg}, \mathrm{K})$ \\
\hline Saturación de AL (\%) & $\ldots$ & $\ldots$ & $\ldots$ & $(\mathrm{Al} / \mathrm{CICE}) * 100$ \\
\hline Saturación de Ca (\%) & 84,35 & 84,55 & 87,45 & $(\mathrm{Ca} / \mathrm{CICE}) * 100$ \\
\hline Saturación de $\mathrm{Mg}(\%)$ & 15,26 & 15,30 & 12,37 & $(\mathrm{Mg} / \mathrm{CICE}) * 100$ \\
\hline Saturación de K (\%) & 0,39 & 0,15 & 0,18 & $(\mathrm{~K} / \mathrm{CICE}) * 100$ \\
\hline Textura & FAa & FAa & FAa & Bouyoucos \\
\hline Contenido de arcilla (\%) & 23,2 & 21,2 & 21,2 & Bouyoucos \\
\hline
\end{tabular}

1 Realizado en el Laboratorio de Análisis de Suelos y Aguas (LABSAS) de la Universidad de Oriente en Maturín, estado Monagas. 
preemergente a las malezas y al cultivo con Dual a razón de 2 1/ha. Además se practicaron dos limpias manuales, una a los 45 días y la otra a los 75 días después de la siembra.

La ETP se calculó promediando los métodos de García y López, Thorhwaite y Blaney-Criddle (cuadro 2). El cuadro 3 muestra las temperaturas medias $\left({ }^{\circ} \mathrm{C}\right)$, la precipitación $(\mathrm{mm})$ y la humedad relativa $(\%)$ registradas durante el desarrollo del ensayo.

Se realizaron cinco riegos de asiento (hasta los 19 días después de la siembra), de manera de establecer la población de los diferentes cultivares. Luego se aplicaron las frecuencias de riego (20 días después de la siembra). La lámina de riego promedio aplicada fue de $366 \mathrm{~mm}$, contando a partir del establecimiento del ensayo y en los cinco riegos de establecimiento se aplicaron $80 \mathrm{~mm}$ de agua aproximadamente, para un total de $440 \mathrm{~mm}$ de agua. En cada riego se aplicó una lámina promedio de 6 $\mathrm{mm} /$ día, tomando en consideración las condiciones de la zona. Como fueron tres frecuencias de riego, por lo tanto, las láminas aplicadas $(\mathrm{Dn}=\mathrm{FR} * \mathrm{ETP}$, donde $\mathrm{Dn}=$ Lámina neta aplicada, $\mathrm{Fr}=$ Frecuencia de riego y ETP = Evapotranspiración potencial) fueron en cada caso: Para la frecuencia de 6 días: $\mathrm{Dn}=6 * 6 \mathrm{~mm}=36 \mathrm{~mm}$; para la frecuencia de 9 días: $\mathrm{Dn}=9 * 6 \mathrm{~mm}=54 \mathrm{~mm}$ y para la frecuencia de 12 días: $\mathrm{Dn}=12 * 6 \mathrm{~mm}=72 \mathrm{~mm}$. El riego por surcos se realizó mediante sifones de 2" y las cargas hidráulicas de trabajo de las mismas fueron calibradas a nivel de campo con un Ballofet, como se conoce el caudal $\mathrm{Q}$ y como $\mathrm{Q}=\mathrm{V} / \mathrm{T}$, donde $\mathrm{V}=$ Volumen de agua aplicada y $\mathrm{T}=$ Tiempo de riego; el $\mathrm{V}$ se puede calcular mediante la ecuación: $\mathrm{V}=\mathrm{A} * \mathrm{Dn}$, de allí que $\mathrm{T}=\mathrm{V} / \mathrm{Q}$, obteniéndose así el tiempo de aplicación para cada frecuencia. Se realizó el análisis de varianza convencional. El nivel de significación fue $5 \%$.

Cuadro 2

Evapotranspiración potencial ( $\mathrm{mm} / \mathrm{día}$ ) promedio mensual correspondiente al periodo de riego con cuatro cultivares de girasol evaluados en parcelas del Sistema de Riego “Santa Elena de las Piñas”, del Río Guarapiche, Maturín, estado Monagas

\begin{tabular}{|l|c|c|c|c|}
\hline \multirow{2}{*}{ Mes } & \multicolumn{3}{|c|}{ Métodos } & \multirow{2}{*}{ Promedio } \\
\cline { 2 - 4 } & Thorhwaite & García y López & Blaney-Criddle & \\
\hline Marzo & 6,00 & 5,85 & 4,11 & 5,32 \\
\hline Abril & 4,75 & 5,95 & 4,35 & 5,02 \\
\hline Mayo & 4,92 & 5,80 & 3,53 & 4,75 \\
\hline
\end{tabular}

Cuadro 3

Temperaturas medias $\left({ }^{\circ} \mathrm{C}\right)$, precipitación $(\mathrm{mm})$ y humedad relativa $(\%)$ registradas en el experimento con cuatro cultivares de girasol evaluados en parcelas del Sistema de Riego "Santa Elena de las Piñas", del Río Guarapiche, Maturín, estado Monagas

\begin{tabular}{|l|r|r|r|r|r|r|r|r|r|r|r|r|}
\cline { 2 - 13 } \multicolumn{1}{c|}{} & \multicolumn{3}{|c|}{ Marzo } & \multicolumn{3}{c|}{ Abril } & \multicolumn{3}{c|}{ Mayo } & \multicolumn{3}{c|}{ Junio } \\
\cline { 2 - 13 } & TM & P & HR & TM & P & HR & TM & P & HR & TM & P & HR \\
\hline TotM & 616,9 & 0,3 & 1418 & 808,6 & 0,0 & 1961 & 841,1 & 10,8 & 2045 & 786,7 & 230,7 & 2425 \\
\hline Prom & 26,8 & & 61,6 & 27,0 & & 62,0 & 27,1 & & 66,0 & 26,2 & & 80,8 \\
\hline ADCC & 616,9 & 0,3 & & 1425,5 & 0,3 & & 2266,6 & 11,1 & & 3053,3 & 241,8 & \\
\hline
\end{tabular}

TM: Temperatura Media $\left({ }^{\circ} \mathrm{C}\right)$ P: Precipitación (mm) HR: Humedad Relativa (\%).

TotM: Total del mes. ADCC: Acumulado durante el ciclo del cultivo.

Fuente: Estación Meteorológica de la Fuerza Aérea Venezolana, Maturín, estado Monagas. 
Se realizó el análisis de varianza convencional y las diferencias entre tratamientos se detectaron mediante la prueba de rangos múltiples de Duncan. El nivel de significación fue $5 \%$.

Se determinaron los siguientes caracteres: días a inicio de floración, días a 50\% de floración, días a cosecha, contenido de aceite en el aquenio, contenido de proteínas en el aquenio y rendimiento de aquenios/planta.

\section{RESULTADOS Y DISCUSIÓN}

No se encontraron diferencias significativas para las fuentes de variación cultivares, frecuencias de riego ni para la interacción de estos dos factores para el contenido de aceite en el aquenio $(29,21 \%)$.

Se encontraron diferencias significativas entre híbridos para los siguientes parámetros: días a inicio de floración, días a 50\% de floración y rendimiento de aquenios/planta. El cultivar más precoz en floración tanto a inicio de la misma como a $50 \%$ de floración fue M-733, mientras que el más tardío para estos dos caracteres fue S-515. Los cultivares GV-28074 y H-18-A podrían clasificarse como intermedios en floración entre los dos cultivares mencionados anteriormente (cuadro 4). En cuanto al contenido de proteínas en el aquenio, el cultivar H-18-A fue el que presentó el menor valor para este carácter (cuadro 4) en comparación con los otros tres cultivares, los cuales no difirieron entre sí para este carácter. El cultivar H-18-A presentó rendimientos de aquenios/planta similares a aquellos de los cultivares M-733 y GV-28074, pero superiores al producido por S-515 (cuadro 4). El mayor contenido de proteínas en el aquenio se registró en las plantas cultivadas en las mayores frecuencias de riego (9 y 12 días), superando al contenido de proteína en el aquenio de las plantas regadas cada 6 días (cuadro 5).

\section{Cuadro 4}

Promedios del número de días a inicio de floración, número de días a $50 \%$ de plantas en floración, contenido de proteínas y rendimiento de aquenios/planta de cuatro cultivares de girasol (Helianthus annuus L.) evaluados en el Sistema de Riego "Santa Elena de las Piñas” del Valle del Río Guarapiche, Maturín, estado Monagas, Venezuela

\begin{tabular}{|l|c|c|c|c|c|c|c|c|}
\hline Cultivares & \multicolumn{2}{|c|}{$\begin{array}{c}\text { Inicio de Floración } \\
\text { (días) }\end{array}$} & \multicolumn{2}{|c|}{$\begin{array}{c}\text { 50\% de Floración } \\
\text { (días) }^{\mathbf{1}}\end{array}$} & $\begin{array}{c}\text { Contenido de Proteínas } \\
(\%))^{\mathbf{1}}\end{array}$ & \multicolumn{2}{c|}{$\begin{array}{c}\text { Rendimiento de } \\
\text { aquenios/planta (g) }\end{array}$} \\
\hline H-18-A & 50,9 & B & 58,0 & C & 17,11 & B & 47,71 & A \\
\hline M-733 & 44,0 & A & 48,8 & A & 18,48 & A & 44,14 & AB \\
\hline GV-28074 & 49,6 & B & 54,0 & B & 18,10 & A & 40,97 & AB \\
\hline S-515 & 57,0 & C & 62,9 & D & 18,86 & A & 37,01 & B \\
\hline
\end{tabular}

$1 \quad$ Prueba de Rangos Múltiples de Duncan $(\mathrm{p}<0,05)$. Letras iguales indican similitud estadística.

\section{Cuadro 5}

Promedios del contenido de proteínas en el aquenio del girasol (Helianthus annuus $\mathbf{L}$.) bajo tres frecuencias de riego evaluados en el Sistema de Riego “Santa Elena de las Piñas” del Valle del Río Guarapiche, Maturín, estado Monagas, Venezuela

\begin{tabular}{|c|c|c|}
\hline Frecuencia de Riego (días) & \multicolumn{2}{|c|}{$\begin{array}{c}\text { Contenido de Proteínas } \\
\text { en el Aquenio (\%) }\end{array}$} \\
\hline 6 & 17,58 & B \\
\hline 9 & 18,39 & A \\
\hline 12 & 18,45 & A \\
\hline
\end{tabular}

1 Prueba de Rangos Múltiples de Duncan $(\mathrm{p}<0,05)$.

Letras iguales indican similitud estadística. 
En la frecuencia de riego de 6 días, el cultivar más precoz fue GV-28074 con 88,0 días, mientras que en la frecuencia de riego de 9 y 12 días, los cultivares más precoces fueron M-733 y GV-28074 con 91,3 y 97,7 días, respectivamente. La comparación dentro de los cultivares indicó que H-18-A tuvo un ciclo de cultivo similar bajo las tres frecuencias de riego, mientras que S-515 y GV-28074 fueron más precoces en la frecuencia de 6 días en comparación con la frecuencia de 9 y 12 días, mientras el cultivar M-733 tuvo una respuesta completamente diferente a la de estos dos cultivares, es decir, este híbrido fue más precoz en las frecuencias de $9 \mathrm{y}$ 12 días en comparación con la frecuencia de 6 días (cuadro 6).

Estos resultados indican que el riego no afectó la precocidad basada en la floración, ya que sólo se encontraron diferencias genéticas entre los híbridos usados, pero los intervalos de riego sí afectaron el ciclo del cultivo de acuerdo al cultivar. Este resultado pudo deberse a que se aplicaron cinco riegos de asiento (hasta los 19 días después de la siembra) que suministraron $80 \mathrm{~mm}$ de agua, por lo que probablemente el suelo contenía similares y adecuadas cantidades de agua, por lo que sólo se manifestaron las características genotípicas de los cultivares en la etapa de floración (entre 44 y 67 días después de la siembra), pero ya en la etapa de cosecha del cultivo se habían aplicado 10, 7 y 5 riegos para las frecuencias de 6, 9 y 12 días, respectivamente, por lo que a pesar de que se aplicó la misma cantidad acumulada de agua en estos riegos $(366 \mathrm{~mm})$, la frecuencia de la aplicación afectó el ciclo del cultivo entre los híbridos evaluados. Méndez-Natera (1990) indicó que el carácter días a floración está más influenciado por factores genéticos que por efectos ambientales bajo las condiciones climáticas de sabana.

En este ensayo, GV-28074 fue más precoz que M-733 en la frecuencia de 6 días y 9 días (aunque en esta última no fue significativa), mientras que en la frecuencia de 12 días sucedió lo contrario (aunque tampoco fue significativo), indicando que la distribución temporal del agua afectó el ciclo del cultivo. Similares resultados en cuanto al ciclo diferencial de estos dos cultivares fueron reportados por el FONAIAP (1993) en ensayos regionales realizados en varias zonas de Venezuela. Estos ensayos reportaron que en Portuguesa, en 1991, los cultivares M-733 y GV-28074 se cosecharon a los 103 y 105 días, respectivamente, mientras que para el año 1992 se cosecharon a los 91 y 92 días, respectivamente, en Maracay; 124 y 111 días, respectivamente, en Barinas, y 101 y 99 días, respectivamente, en Portuguesa, indicando que en dos de los cuatro ensayos M-733 fue más precoz que GV-28074 y viceversa.

Cuando se toma el carácter $50 \%$ de las plantas en floración, el orden de los cultivares desde el más precoz hasta el más tardío es: M-733, GV-28074,

Cuadro 6

Promedios del número de días a cosecha para la interacción frecuencia de riego ${ }^{1}$ cultivar en girasol (Helianthus annuus L.) evaluados en el Sistema de Riego "Santa Elena de las Piñas" del Valle del Río Guarapiche, Maturín, estado Monagas, Venezuela

\begin{tabular}{|l|c|c|c|c|c|c|}
\hline \multirow{2}{*}{ Cultivares } & \multicolumn{7}{|c|}{ Número de Días a Cosecha1 $^{\text {Frecuencia de Riego (días) }}$} \\
\cline { 2 - 7 } & \multicolumn{7}{|c|}{$\mathbf{6}$} & \multicolumn{2}{c|}{$\mathbf{9}$} & \multicolumn{2}{c|}{$\mathbf{1 2}$} \\
\cline { 2 - 7 } M-733 & 105,7 & $\mathrm{ABa}$ & 96,0 & $\mathrm{Bb}$ & 91,3 & $\mathrm{Bb}$ \\
\hline GV-28074 & 88,0 & $\mathrm{Cb}$ & 91,7 & $\mathrm{Bab}$ & 97,7 & $\mathrm{Ba}$ \\
\hline H-18-A & 109,7 & $\mathrm{Aa}$ & 111,0 & $\mathrm{Aa}$ & 111,7 & $\mathrm{Aa}$ \\
\hline S-515 & 100,7 & $\mathrm{Bb}$ & 110,0 & $\mathrm{Aa}$ & 111,7 & $\mathrm{Aa}$ \\
\hline
\end{tabular}

1 Prueba de Rangos Múltiples de Duncan ( $\mathrm{p}<0,05)$.

Letras iguales indican similitud estadística.

Letras mayúsculas para las comparaciones verticales.

Letras minúsculas para las comparaciones horizontales. 
H-18-A y S-515. En un ensayo realizado por CortezGarcía (1998) con seis cultivares de girasol en la sabana de Jusepín, en época de lluvias encontró que los cultivares más precoces a floración a los 40 días después de la siembra fueron M-734 y GV-28074 y uno de los más tardíos fue S-407, es decir, los cultivares tuvieron un orden similar en ambos ensayos tomando en consideración la casa liberadora del cultivar.

Como se ha visto en este ensayo el riego afecta el ciclo total del cultivo (desde la germinación hasta la maduración) en el girasol dependiendo del cultivar empleado. Anwar et al. (1995), en ensayos de campo en Pakistán en 1986-1987, regaron los cultivares de girasol NK-212 y Record, 1, 2, 3, 4 o 5 veces y encontraron que todos los componentes del rendimiento fueron afectados por el número de riegos. A medida que se incrementó el número de riegos se incrementó el número de días a maduración, diámetro del capítulo, altura de la planta, peso de 1.000 semillas y los rendimientos de semillas y tallos, NK-212 maduró más precozmente que Record y fue menos afectada por el riego y así fue recomendada para cultivarse en las regiones áridas de Pakistán. Tomar et al. (1995), en un experimento de campo conducido en India para estudiar el efecto del riego y los fertilizantes nitrogenados y fosforados (como fosfato diamónico y urea) sobre las etapas fisiológicas del girasol de primavera, encontraron que riegos más frecuentes y dosis altas de nitrógeno y fósforo retrasaron las etapas fisiológicas de este cultivo.

El contenido de aceite en el aquenio no fue afectado por las diferentes frecuencias de riego y fue similar en los cuatro híbridos, aunque en promedio fue relativamente bajo $(29,21 \%) \mathrm{com}-$ parado con otros estudios realizados en Venezuela. El FONAIAP (1993) reportó contenidos de aceite en el aquenio para el cultivar GV-28074 de 34, 35, 34, 37 y $36 \%$ en las localidades de Maracay, Mazparrito, Libertad, La Atahona, Valle de la Pascua y El Candil, respectivamente, y valores de $38,33,38,44$ y $41 \%$, respectivamente, para el híbrido M-733 en estas mismas localidades. Esto pudo deberse a que nuestro ensayo se realizó en la época seca donde las temperaturas son más altas que en la época de lluvias cuando se realizaron los ensayos del FONAIAP cuando las temperaturas son más bajas, debido a que Zhdanova, citado por Mazzani (1983), indicó que a menores temperaturas hay más aceite y menos proteínas en los aquenios de girasol. Por otra parte, el contenido de proteínas en el aquenio varió entre 17,11 y $18,86 \%$, valores que están dentro del rango de variación citado por Mazzani (1983) de 15,4 a 22,6\% de proteínas en un estudio con 14 cultivares de girasol. Por otro lado, resultados similares fueron indicados por Cortez-García (1998), quien no encontró diferencias significativas entre seis híbridos evaluados en Jusepín en época de lluvias, los cuales tuvieron un promedio general de $30,8 \%$, valor similar al encontrado en nuestro ensayo, mientras resultados diferentes fueron obtenidos por Méndez-Natera y Cedeño (1996), quienes trabajando con 16 cultivares de girasol encontraron que el contenido de aceite varió de acuerdo al cultivar; el menor contenido de aceite fue para Contiflor 3 (aceitero) y Biondi (confitero) con 26,61 y $25,74 \%$, respectivamente, y el mayor fue para los cultivares M-702 (aceitero) y DO-728 (aceitero) con 39,94 y 39,91\%, respectivamente, siendo estos dos últimos valores muy superiores al obtenido en nuestro ensayo.

Las frecuencias de riego afectaron el contenido de proteínas. Siendo más alto en las mayores frecuencias de riego ( 9 y 12 días) este resultado es contradictorio, ya que se esperaría una disminución en el contenido de aceite en las mayores frecuencias de riego, ya que Vrậnceanu (1977) expresa que conocido el antagonismo entre la biosíntesis del aceite y de las proteínas, se entiende que los factores ambientales o de cultivo que favorezcan la formación y acumulación intensa de aceite actúan en detrimento del contenido relativo de proteínas y a la inversa. Pero en este ensayo el contenido de aceite tuvo una tendencia similar a la del contenido de proteínas, ya que los promedios del contenido de aceite fueron 28,$64 ; 28,67$ y $30,32 \%$ para las frecuencias de riego de 6,9 y 12 días, respectivamente, aunque estas diferencias no fueron a nivel estadístico. Resultados también diferentes fueron reportados por Putnam et al. (1990) quienes indicaron que un tiempo crítico para el estrés hídrico es el periodo de 20 días antes y 20 días después de la floración y si el estrés ocurre en este periodo, el riego incrementaría el rendimiento, el porcentaje de aceite y el peso de la semilla pero disminuiría el porcentaje de proteínas.

El contenido de proteínas también varió de acuerdo al cultivar empleado. Sin importar los intervalos de riego, tres cultivares tuvieron contenidos de proteínas por encima del $18 \%$, sin diferencias significativas entre ellos. Resultados diferentes fueron reportados por Cortez-García (1998). Evaluando seis cultivares 
de girasol, entre ellos GV-2074, el promedio general fue $16,69 \%$, valor inferior al encontrado para todos los cultivares en nuestro ensayo.

Estos resultados no concuerdan con los reportados en la literatura con respecto al incremento del contenido de aceite con la aplicación de riego. Alba-Ordóñez y Llanos-Company (1990) indicaron que el estrés hídrico produce un descenso en el contenido de aceite de las semillas de girasol y Vrânceanu (1977) reportó que uno de los efectos negativos de la sequía se manifiesta también de forma evidente sobre la acumulación de aceite en las semillas, es decir, hay una disminución del contenido de aceite. Estos resultados indican que los mayores intervalos de riego ( 9 y 12 días) no ocasionaron un estrés hídrico en las plantas de girasol, por lo que el contenido de aceite no se vio afectado por el riego. Karami (1977), en ensayos realizados en 1973 y 1974 con el cultivar de girasol Record sembrado a 15, 20, 25 o $30 \mathrm{~cm}$ entre plantas y regado cada $6,12,18$ o 24 días, encontró que el contenido de aceite de la semilla disminuyó con los intervalos de riego más largos. Kandil (1984), en experimentos de campo durante 1982-1983 en Giza, Egipto, encontró que los cultivares Giza 1 y H-167 fueron regados a intervalos de 7, 14 o 21 días y que el contenido de aceite varió de 37,5-38,2; $36,7-37,4$ y $34,8-35,1$ para las frecuencias de riego de 7,14 y 21 días, respectivamente, y el rendimiento de aceite fue de 24,3-24,7; 17,5-20,6 y 17,1-17,5 g por planta, respectivamente. Tomar et al. (1996) condujeron un experimento de campo durante dos años (1992-1993) en un suelo limoso en India para evaluar la influencia de tres niveles de riego $(0,4 ; 0,6$ y 0,8 de la relación agua de riego/evaporación de la tina), tres niveles de nitrógeno (40, 80 y $120 \mathrm{~kg} / \mathrm{ha})$ y tres de fósforo $\left(0,40\right.$ y $80 \mathrm{~kg}$ de $\mathrm{P}_{2} \mathrm{O}_{5} / \mathrm{ha}$ ) sobre el contenido de proteínas y de aceite del cultivar de girasol Morden y encontraron que el contenido de aceite aumentó con incrementos en los niveles de riego y el máximo $(42,57 \%)$ se obtuvo con una relación de agua de riego/evaporación de la tina de 0,8 , mientras el contenido de proteína disminuyó con los niveles más altos de riego. Por su parte, Shahid-Rafiq et al. (1998), en un experimento en 1994 en Pakistán, el cultivo de girasol fue regado 6 u 8 veces a intervalos de 7 o 14 días cubriendo las etapas iniciales o tardías del desarrollo y encontraron que el rendimiento de semillas, el contenido de aceite en la semilla y los valores de los componentes del rendimiento fueron más altos con 8 riegos a intervalos de 7 días entre los 14 y 63 días después de la siembra. Sin embargo, Abdel-Gawad et al. (1987), en un experimento de campo en 1983-1984 con lo cultivares de girasol Giza 1, Zaher-el-haia, Miak y Peredovik regados cada 10, 14 o 18 días, comenzando a los 18 días después de la siembra, encontraron que el intervalo de riego de 14 días produjo el contenido más alto de aceite en la semilla en todos los cultivares. Anwar et al. (1995) regaron los cultivares de girasol NK-212 y Record, 1, 2, 3, 4 o 5 veces y encontraron que el contenido de aceite se incrementó con hasta 4 riegos y entonces disminuyó. Con la excepción del rendimiento de semillas y el contenido de aceite, Record se comportó mejor que NK-212. Más recientemente, Erdemoglu et al. (2003) encontraron que el riego incrementó el rendimiento de semillas, el rendimiento de aceites y el contenido de aceite en dos poblaciones, una variedad sintética y la mezcla de tres líneas de girasol. En tanto, y Kniss et al. (2005) determinaron el contenido de aceite del 2002 al 2004 y encontraron que este fue 40,$3 ; 40,1 ; 39,0$ y $35,8 \%$ para la aplicación de un riego cada semana, dos semanas, tres semanas y sin riego, respectivamente, mientras que en este ensayo fueron 28,$64 ; 28,67$ y $30,32 \%$ para un riego cada 6 , 9 y 12 días, respectivamente. Resultados similares al obtenido en este ensayo fueron reportados por Nel (2001) en relación a que el contenido de aceite de la semilla no fue afectado por el tratamiento de estrés hídrico al cultivo pero sí entre cultivares. Este autor indicó que este resultado contradijo los resultados de otros investigadores debido a que el estrés hídrico durante las etapas de crecimiento vegetativo y reproductivo reduce el contenido de aceite, pero que el contenido de proteína de la semilla, sin embargo, parece ser menos afectado por el estrés hídrico después de antesis que el contenido de aceite. Los resultados obtenidos en este ensayo también contradicen completamente la anterior asunción, partiendo del hecho de que existiese estrés hídrico en este ensayo. Este sería mayor en la frecuencia más alta de riego (12 días).

Por otra parte, Debaeke et al. (1998) estudiaron cinco diferentes opciones de manejo en el girasol en un periodo de 10 años (1984-1994) en un suelo profundo arcillo limoso en Francia, combinando diferentes niveles de densidad de población del cultivo, aplicación de fertilizante nitrogenado y riego suplementario y encontraron que la concentración de aceite fue generalmente más alta bajo una irrigación completa, pero valores altos también fueron 
observados bajo condiciones de secano, indicando que se utilizó un genotipo apropiado.

Las frecuencias de riego no afectaron el rendimiento de aquenios por planta, pero sí hubo diferencias entre cultivares. Resultados similares fueron indicados por Cortez-García (1998) en seis cultivares de girasol evaluados bajo condiciones de sabana con rendimientos variando de 14,6 g/planta (GV-28074) a 57,5 g/planta (Tesoro); el rendimiento del cultivar GV-28074 en nuestro ensayo fue dramáticamente superior (41,0 g/planta) al observado por Cortez-García, sugiriendo un posible efecto beneficioso del riego para este cultivar, mientras que Méndez-Natera y Cedeño (1996) encontraron diferencias para este carácter. Trabajando con 16 cultivares de girasol en San Jaime, los rendimientos variaron de 18,7 g/planta en el cultivar M-702 a 44,2 g/planta en el cultivar EM-7001, rendimientos menores al obtenido en nuestro ensayo para el mejor cultivar (H-18-A con 47,7 g/planta). También cabe señalar que se obtuvieron resultados similares para este carácter en cultivares provenientes de la misma compañía, por ejemplo, en nuestro ensayo S-515 tuvo un rendimiento de $37,0 \mathrm{~g} / \mathrm{planta}$ y en el ensayo de Méndez-Natera y Cedeño el cultivar S-401 rindió $37,6 \mathrm{~g} / \mathrm{planta}$. Esto no sucedió con respecto al cultivar M-733, el cual rindió 44,1 g/planta en nuestro ensayo y en el ensayo de Méndez-Natera y Cedeño los cultivares M-731, M-732 y M-702 rindieron 27,$4 ; 24,7$ y $18,7 \mathrm{~g} / \mathrm{planta}$, respectivamente.

Resultados diferentes en cuanto a los intervalos de riego fueron reportados por El Din et al. (1994), quienes en un experimento de campo en 1990-1991 en Egipto, trataron al cultivar de girasol Mayak con 15,30 o $45 \mathrm{~kg}$ de $\mathrm{N} /$ feddan y 15 o $30 \mathrm{~kg}$ de $\mathrm{P}_{2} \mathrm{O}_{5} /$ feddan y regado cada 9, 18 o 27 días y encontraron que el rendimiento de semillas por planta fue más alto con los riegos cada 18 y 9 días en 1990 y 1991, respectivamente. Mientras el rendimiento de semillas por parcela no fue afectado por el riego, la altura de la planta y el diámetro del tallo en ambos años y el diámetro del capítulo y el peso de 1.000

\section{LITERATURA CITADA}

ABDEL-GAWAD, A. A.; ASHOUB, M. A.; SALEH, S.A. AND ELGAZZAR. M. M. 1987. Yield response of some sunflowers cultivars to irrigation intervals. Annals of Agricultural Science (Ain Hams University) 32 (2): 1129-1242.

ALBA-ORDÓÑEZ, A. Y LLANOS-COMPANY, M. 1990. El cultivo del girasol. Ediciones Mundi-Prensa, Madrid, España. 158 p. semillas en 1991 sólo fueron más altos con el riego más frecuente.

\section{CONCLUSIONES}

El riego no afectó el contenido de aceite y los cuatro cultivares no difirieron para este carácter y la interacción entre estos dos factores fue no significativa, el promedio general para el contenido de aceite fue $29,21 \%$. El cultivar H-18-A presentó el menor contenido de proteínas en comparación con los otros tres cultivares, los cuales no difirieron entre sí. El mayor contenido de proteínas se registró en plantas cultivadas en las frecuencias de riego de 9 y 12 días, superando al de las plantas regadas cada 6 días.

El cultivar más precoz en floración fue M-733, mientras que el más tardío fue S-515. En la frecuencia de riego de 6 días, el cultivar más precoz fueron GV28074, mientras que en la frecuencia de riego de 9 y 12 días, los cultivares más precoces fueron M-733 y GV-28074, respectivamente. La comparación dentro de los cultivares indicó que H-18-A tuvo un ciclo de cultivo similar bajo las tres frecuencias de riego, mientras que S-515 y GV-28074 fueron más precoces en la frecuencia de 6 días en comparación con la frecuencia de 9 y 12 días, mientras el cultivar M-733 fue más precoz en las frecuencias de 9 y 12 días en comparación con la frecuencia de 6 días. El cultivar H-18-A presentó rendimientos de aquenios/ planta similares a los de M-733 y GV-28074, pero superiores al de S-515.

Para otros estudios similares se recomienda utilizar intervalos de riego mayores y establecer las frecuencias de riego más temprano, con sólo uno o dos riegos de asiento.

\section{AGRADECIMIENTO}

Al Consejo de Investigación de la Universidad de Oriente por el soporte dado al primer autor.
ANWAR, M.; RAHMAN, S.; KHAN, S. AND QUARISH, Z. 1995. Response of sunflower varieties to different irrigation regimes during kharif season in Peshawar Valley. Sarhad Journal of Agriculture 11 (3): 273-278.

CORTEZ-GARCÍA, A. L. 1998. Evaluación agronómica de seis cultivares de girasol (Helianthus annииs L.), en condiciones agroecológicas de sabana, en época de lluvias. Trabajo de 
Grado para Ingeniero Agrónomo. Escuela de Ingeniería Agronómica. Universidad de Oriente. 166 p.

DEBAEKE, P.; CABELGUENNE, M.; HILAIRE, A. AND RAFFAILLAC, D. 1998. Crop management systems for rainfed and irrigated sunflower (Helianthus annиus) in south-western France. Journal of Agricultural Science 131 (2): 171-185.

ERDEMOGLU, N.; KUSMENOGLU, $\mathbf{S}$ AND YENICE, $\mathbf{N}$. 2003. Effect of irrigation on the oil content and fatty acid composition of some sunflower seeds. Chemistry of Natural Compounds 39 (1): 1-4.

EL DIN, N. A. N.; ABD EL HALIM, A. A.; IBRAHIM, K. I. M. AND OUDA, S. A. H. 1994. Performance of sunflower under some ecoagricultural factors. Annals of Agricultural Science (Cairo) 39 (2): 633-647.

FONDO NACIONAL DE INVESTIGACIONES AGROPECUARIAS (FONAIAP). 1993. Ensayos regionales de girasol. Años 1991-1992. Serie D. No 11. s/p.

KANDIL, A. A. 1984. "Sunflower head development affected by irrigation intervals". Annals of Agricultural Science (Moshtohor) $22 \mathrm{~N}^{\mathrm{o}}$ 1, pp. 3-13.

KARAMI, E. 1977. Effect of irrigation and plant population on yield and yield components of sunflower. Indian Journal of Agricultural Sciences 47 (1): 15-17.

KNISS, A. R.; ALFORD, C. M.AND MILLER, S. 2005. Irrigation management in sunflower. Publication B-1166. Cooperative Extension service. University of Wyoming. 4 p.

MAZZANI, B. 1983. Cultivo y mejoramiento de plantas oleaginosas. Publicaciones FONAIAP. Caracas, Venezuela. 629 p.

MÉNDEZ-NATERA, J. R. 1990. Comportamiento agronómico de 16 cultivares de girasol (Helianthus annuus L.) probados en condiciones ecológicas de sabana en San Jaime, Estado Monagas, en época de norte. Trabajo de Grado para Ingeniero Agrónomo. Escuela de Ingeniería Agronómica. Universidad de Oriente. Jusepín, Venezuela. 386 p.
MÉNDEZ-NATERA, J. R. Y CEDEÑO, J. R. 1996. Comportamiento agronómico de 16 cultivares de girasol (Helianthus annuus L.) bajo condiciones agroecológicas de sabana en el Estado Monagas. Oriente Agropecuario 21: $125-137$.

NEL, A. A. 2001. Determinants of sunflower seed quality for processing. Doctoral Thesis. Plant Production: Agronomy. University of Pretoria. $115 \mathrm{p}$.

PUTNAM, D. H.; OPLINGER, E. S.; HICKS, D. R.; DURGAN, B. R.; NOETZEL, D. M.; MERONUCK, R. A. DOLL, J. D. AND SCHULTE, E. E. 1990. Sunflower. Alternative Field Crops Manuals.

http://www.hort.purdue.edu/newcrop/afcm/sunflower.html Última visita 10 de enero de 2006.

SAUMELL, H. 1980. Girasol. Técnicas actualizadas para su mejoramiento y cultivo. Segunda Edición. Editorial Hemisferio Sur, S. A. Buenos Aires, Argentina. 161 p.

SHAHID-RAFIQ, CH.; KHAN, M. A.; SHAH, S. M. AND MALIK, M. A. 1998. Studies on irrigation scheduling in spring sown sunflower (Helianthus annuиs L.). Sarhad Journal of Agriculture 14 (3): 193-197.

SHIV RAJ, A. 1985. An introduction to physiology of field crops. Reprinted 1985. Oxford \& IBH Publishing CO, New Delhi, India. p. 134-139.

TOMAR, H. P. S.; DADHWAL, K. S. AND SINGH, H. P. 1995. Effect of irrigation, nitrogen and phosphorus on physiological stages of spring sunflower. Indian Journal of Soil Conservation 23 (1): 84-85

TOMAR, H. P. S.; DADHWAL, K. S. AND SINGH, H. P. 1996. Oil content, oil and cake yield and protein content of sunflower (Helianthus annuus L.) as influenced by irrigation, nitrogen and phosphorus levels. Indian Journal of Soil Conservation 24 (3): 215-220.

VRÂNCEANU, A. V. 1977. El girasol. Traducido por A. Guerrero, M. León, L. López y J. Fernández. Ediciones Mundi-Prensa, Madrid, España. 379 p. 